\section{Fotografar para Compreender: Relato de Experiência e Reflexões a partir das Lentes Trabalho, Gestão e Subjetividade}

\author{
Laura Alves Scherer, Marcia Cristiane Vaclavik e Carmem Ligia Iochins \\ Grisci
}

\section{RESUMO}

O presente artigo parte da ideia de que os modos de trabalhar têm implicações diretas na constituição do sujeito, e constitui-se de um relato de experiência referente a uma atividade fotográfica desenvolvida em disciplina de um Programa de Pós-Graduação em Administração. Objetiva refletir sobre o uso da fotografia como potencializador da compreensão teórica em Administração. Aproxima-se, assim, do conceito de autoetnografia de Jones (2005) que busca tecer conexões entre vida e arte, experiência e teoria. O artigo apresenta um panorama teórico sobre "fotografia" e "trabalho, gestão e subjetividade", que embasou as atividades realizadas na disciplina. Desenvolvemos reflexões a partir de duas narrativas a respeito da vivência desafiadora de fotografar práticas de trabalho e de gestão no cotidiano. Discutimos acerca dos modos de estudar, considerando os múltiplos papéis a que são desafiados os integrantes de pós-graduação nos contextos de ensino-aprendizagem, pesquisa e extensão. Argumentamos em favor da interação da arte com a produção científica, por entender que a experiência levou à qualificação do olhar e, assim, possibilitou novas formas de apreensão da teoria em campo.

Palavras-chave: Fotografia; Relato de Experiência; Trabalho; Gestão; Subjetividade.

\section{Photographing to Understand: Experience Report and Reflections from the Lens of Work, Management and Subjectivity}

\section{ABSTRACT}

The present paper starts from the idea that the ways of working have direct implications in the constitution of the person, and is constituted of an experience report referring to a photographic activity developed in discipline of a Postgraduate Program in Administration. It aims to reflect about the use of photography as a lever of theoretical understanding in Administration. Thus, it approaches at Jones's (2005) concept of autoethnography that seeks to weave connections between life and art, experience and theory. The paper presents a theoretical panorama about "photography" and "work, management and subjectivity", which supported the activities carried out in the discipline. We developed reflections based on two narratives about the challenging experience of photographing work and management practices in everyday life. We discuss ways of studying, considering the multiple roles that postgraduate students are challenged in teaching-learning, research and extension contexts. We argue in favor of the interaction of art with scientific production, by understanding that experience led to the look qualification and, therefore, enabled new forms of apprehension of theory in the field.

Keywords: Photography; Experience Report; Work; Management; Subjectivity.
Recebido em: 21/12/2017 Aprovado em: 09/04/2018 Última Modificação: 22/06/2018

Check for updates

Laura Alves Scherer (iD, Professora do Curso de Administração da Universidade Federal do Pampa, Santana do Livramento, Brasil. Doutoranda em Administração pela Universidade Federal do Rio Grande do Sul, Brasil.

lauralvescherer@gmail.com

\section{Marcia Cristiane}

Vaclavik (iD,

Coordenadora do Curso de Tecnologia em Logística no Centro Universitário UNICNEC, Osório, Brasil. Doutoranda em Administração pela Universidade Federal do Rio Grande do Sul, Brasil.

mcvaclavik@gmail.com

\section{Carmem Ligia lochins} Grisci (iD,

Professora do Programa de Pósgraduação em Administração da Universidade Federal do Rio Grande do Sul, Brasil.

Doutora em Psicologia pela Pontifícia Universidade Católica do Rio Grande do Sul, Brasil. Pesquisadora PQ 1D. CNPq/Brasil Processo n. 302978/2014-3.

carmem.grisci@ufrgs.br 


\section{Introdução}

Os modos de trabalhar têm implicações diretas na constituição do sujeito. Atualmente, demandam um trabalhador autônomo, polivalente, flexível, mobilizado e engajado na tarefa, gestor de si diante da nova relação produção-consumo que vem a caracterizar o trabalho imaterial como aquele exigente da subjetividade (Gorz, 2005; Lazzarato \& Negri, 2001). No campo da subjetividade, há de se considerar que tomar a "subjetividade em suas conexões com o trabalho implica pensar os modos como as experiências do trabalho conformam modos de agir, pensar, sentir e trabalhar" (Tittoni \& Nardi, 2011, p. 377). E, no campo da Administração, há de se ponderar que a realidade organizacional transpõe a interação puramente instrumental e lógica, dizendo respeito, também, a vivências que envolvem sensações e sentimentos por vezes antagônicos (Davel, Vergara \& Ghadiri, 2007).

Nesse sentido, argumentamos, conjuntamente com Maurente e Tittoni (2007), que integrar a sensibilidade da arte à produção científica é uma forma de reagir às imposições da racionalidade moderna. E, no tocante ao processo de ensino-aprendizagem e pesquisa relativos à Administração, consideramos, ao encontro de Davel, Vergara e Ghadiri (2007), que a arte, com seu poder perturbador, provocador e inspirador, é elemento que pode ampliar os sentidos e contribuir para a formação de um sujeito reflexivo e crítico. Ao lado do cinema, da literatura, das belas artes, do teatro, da música e da dança, também a fotografia, conforme Junquilho e Gonçalves (2007, p. 28), tem se mostrado um recurso para fazer "emergir uma consciência crítica fundamentada na realidade circundante".

Ao considerar a fotografia "um instrumento eficiente para a produção do conhecimento em Ciências Sociais", Guran (2011, p. 22) ressalta o desafio epistemológico que o conhecimento associado à prática fotográfica apresenta. A fotografia contribuiria, por exemplo: para uma nova lógica científica a destacar a dimensão subjetiva de uma pesquisa (Guran, 2011); para descortinar os não-ditos organizacionais (Cavedon, 2005); para permitir o desenvolvimento de novos insights teóricos nos estudos em Administração (Ray \& Smith, 2012).

Ao relatarem sua experiência com a utilização de imagens fotográficas no campo de pesquisa, Maurente e Tittoni (2007, p. 36) instigam a "fotografar para pensar". Esse é o mote adotado pelo presente artigo que busca refletir sobre o uso da fotografia como potencializador da compreensão teórica em Administração. Para tanto, optamos por relatar experiências vividas pelas autoras em uma disciplina de um Programa de Pós-Graduação em Administração, valendo-se de uma construção textual-imagética. Ao experimentar modos de estudar tão peculiares nesta área de conhecimento, surgiu o desejo de compartilhar desafios e reflexões provocados pela utilização da arte fotográfica em conexão com os pilares ensino-aprendizagem, pesquisa e extensão.

A seguir, apresentamos (i) o panorama teórico que versa sobre "fotografia" e "trabalho, gestão e subjetividade" e embasou as atividades realizadas em sala de aula; (ii) a experiência relativa ao desafio de fotografar composta por duas narrativas; (iii) uma reflexão sobre as vivências relatadas; (iv) e as considerações finais. 


\section{Fotografia}

O uso de imagens fotográficas em pesquisa é prática recorrente e consolidada em diversos campos do conhecimento ${ }^{1}$. Cavedon (2005) e Flick (2009) ressaltam a longa tradição da fotografia na Antropologia e na etnografia, enquanto Maurente e Tittoni (2007) citam a Comunicação Social, a Psicologia, a Educação e a Sociologia como áreas em que a fotografia tem sido cada vez mais utilizada como recurso metodológico. Godoi e Uchoa (2016) mencionam que a incorporação recente de objetos audiovisuais, dentre os quais a fotografia, também se encontra na área de Estudos Organizacionais.

A respeito do crescente uso da fotografia como registro documental e de seu entendimento como ferramenta tecnológica de fácil manipulação e fluxo de informações e de amplo acesso, Uchoa e Godoi (2016) revelam uma disputa entre a imagem e as palavras. Sobre o potencial reflexivo e investigativo da fotografia, Maurente e Tittoni (2007) consideram que a mesma vem sendo utilizada frequentemente apenas como elemento secundário e ilustrativo. Para Samain (2012), desde a infância somos levados a dar mais credibilidade às letras, palavras e frases, uma vez que, sendo domáveis por obedecerem às regras gramaticais, seriam também mais sérias e confiáveis. As imagens, por sua vez, "inquietantes, intrigantes e insistentes" (Samain, 2012, p. 154), não adquiriram, ainda, verdadeiro peso na balança do conhecimento.

Ao tomar a fotografia como recurso pedagógico, Demo (2001) lembra que há de se considerar a indissociabilidade entre pesquisa e ensino, e pensar a pesquisa inserida na prática ao longo do processo educativo. $O$ uso da arte na sala de aula (onde se inclui a fotografia, além de cinema, belas artes, literatura, música, teatro e dança) representa, para Paço-Cunha (2009), uma possibilidade de rompimento com as práticas docentes habituais e de transformação da relação professor-aluno. Para o autor, por meio da arte "a pessoa se expressa e ao fazê-lo, modifica a si mesma" (Paço-Cunha, 2009, p. 700).

Para Madden e Smith (2015, p. 117, tradução livre), a utilização da fotografia em sala de aula, em especial no campo da Administração, possibilita aos alunos "desenvolver diferentes perspectivas para compreender o mundo", bem como "desenvolver o senso de identidade, de contribuição para o mundo e de esperanças para o futuro". Estes autores citam que, apesar da fotografia ser menos utilizada em classe do que outras formas de arte (como filmes e desenhos), não se deve desconsiderar a importância que ela possui nas pesquisas sociais, em especial na Sociologia, na Antropologia e em Estudos Organizacionais, reforçando a importância do vínculo entre pesquisa e ensino, também enfatizado por Demo (2001).

Madden e Smith (2015) trazem, ainda, três diferentes possibilidades para o uso da fotografia em sala de aula, quando os alunos: a) utilizam imagens prontas, provenientes de arquivos; b) são instigados a refletir sobre

\footnotetext{
1 Para mais detalhes sobre o percurso histórico da fotografia e de outros recursos imagéticos na pesquisa científica, bem como mais referências sobre o tema, recomenda-se a leitura de Flick (2009); Ipiranga (2016) e Uchoa e Godoi (2016). Não é objeto do presente estudo esgotar as discussões sobre a utilização da fotografia no campo científico.
} 
fotografias que eles mesmos produzem durante uma investigação; e c) além de produzirem suas próprias fotografias, são incentivados a participar de projetos de longa-duração em que os resultados são apresentados à comunidade, de forma que possam contribuir para uma mudança social no meio em que vivem.

Assim, valendo-se do que foi apontado por Fernandes (2011) sobre o uso da fotografia pelo pesquisador, ressalta-se que este mesmo entendimento vale também para a relação professor-aluno no exercício da prática pedagógica.

Sendo a imagem apenas parte do todo capaz de ser percebido pelo olho humano, ao se utilizar da fotografia como uma fonte a mais para a leitura da realidade, o pesquisador vai se cercar dos recursos de que dispõe, de modo a ser capaz de transformar um objeto inerte (a fotografia) numa linguagem plena de significação. Nesse exercício de aproximação subjetiva e recuo objetivo, na tentativa de perscrutar para além da imagem, o pesquisador, tal como o artesão, vai tecendo os fios das teorias, das técnicas e da epistemologia, em busca da centelha que lance luz sobre o detalhe, o imperceptível, para descobrir o que se esconde sob a evidência empírica. (Fernandes, 2011, p. 49).

A seguir, compartilhamos a base de estudo adotada na disciplina, que indica o caminho reflexivo deste relato de experiência.

\section{Trabalho, Gestão e Subjetividade}

As formas de organizar, gerir e produzir dizem das diferentes configurações do trabalho contemporâneo ao demandarem organizações e trabalhadores flexíveis, bem como das implicações à constituição do sujeito. Os modos como esse sujeito atribui sentido a suas experiências laborais tem a ver com a relação trabalho e subjetividade (Tittoni \& Nardi, 2011).

Diante das transformações que sofrem o modo de acumulação, as organizações e o trabalho propriamente dito, ressalta-se o trabalho imaterial "sempre mais" requisitado (Lazzarato \& Negri, 2001) na lógica que ilustra o trabalhador "gestor de si" na nova relação produção-consumo (Gaulejac, 2007). Deste sujeito que trabalha é esperado que não se limite a obter conhecimentos ou qualificações profissionais. Dele é esperado que disponha de qualidades de comportamento expressivas e imaginativas, do envolvimento pessoal na tarefa que lhe cabe desenvolver e completar (Gorz, 2005). No novo management é a sua personalidade, sua subjetividade que deve ser organizada e comandada. Qualidade e quantidade de trabalho são, assim, reorganizadas em torno de sua imaterialidade (Lazzarato \& Negri, 2001).

O trabalho imaterial se refere ao conjunto de atividades corporais, intelectuais, criativas, afetivas e comunicativas inerentes ao trabalhador, à mobilização das características pessoais dos trabalhadores, à interatividade e afetividade voluntariamente geridas por si e colocadas à disposição da acumulação do capital e da relação produção-consumo (Lazzarato \& Negri, 2001; Gorz, 2005; Grisci, 2011). Os modos como os trabalhadores incorporam esses saberes não podem ser premeditados ou ditados: exigem o investimento de si mesmo, aquilo que na linguagem empresarial é chamado de "motivação" (Gorz, 2005, p. 9). 
Destaca-se a complexidade da transformação de um trabalhador disciplinado, outrora atrelado à divisão e especialização do trabalho, cujas capacidades de gerenciamento e iniciativa se viam desvalorizadas no modo de produção taylorista-fordista, que agora se vê demandado na totalidade da vida (Deleuze, 1992; Grisci, 2011). Em linha com este argumento, Mansano (2009) e Mansano e Carvalho (2015) apontam um sujeito que transita entre o trabalho material e o imaterial, em maior ou menor grau, em todas as profissões, ilustrando múltiplas políticas de subjetivação.

Gaulejac (2007) atenta para a gestão da subjetividade, aquela que mobiliza o indivíduo por meio da "autoestima, da autonomia, do reforço narcísico, da reflexividade", canalizando os investimentos psíquicos para objetivos de rentabilidade e de desempenho. Na ideologia da realização de si mesmo, o ser humano utiliza-se do seu potencial de desenvolvimento, colocando-se em sinergia com os propósitos de rentabilidade da organização. Uma boa gestão de si mesmo, na perspectiva da autorrentabilização, seria, portanto, o fator chave do sucesso, tanto do indivíduo, como da empresa (Gaulejac, 2007).

Trabalhar é produzir-se, ou seja, o operador deve doar-se ou entregar-se de maneira contínua à gestão, produzindo-se como sujeito para assumi-la. É o advento do autoempreendedor, em que o trabalhador atua como empreendedor, qualquer que seja seu estatuto, na gestão das suas capacidades consideradas como seu capital fixo (Gorz, 2005). Torna-se uma empresa: no lugar daquele que depende de salário, vê-se o empresário da força de trabalho, que providencia o seu próprio aperfeiçoamento. Ocorre, então, uma migração da relação empregador-empregado para uma relação em que as grandes empresas se tornam clientes do autoempresário anunciado como Eu S/A (Gorz, 2005).

Nesse cenário de autocomercialização e concorrência, é necessário estar sempre em movimento, já que a satisfação consigo mesmo dificilmente é alcançada de forma plena. As condições de incerteza geram o temor de não conseguir acompanhar a rapidez dos eventos e ficar para trás. Gaulejac (2007, p. 87) aponta que, nessa nova fase capitalista em que vivemos, conviver com os "fracassos, crises e reestruturações" é algo já naturalizado pelo sujeito que, na falta de segurança e de garantias, enfrenta a flexibilidade do sistema econômico fazendo eclodir uma "subjetividade fluida, capaz simultaneamente de se mobilizar maciçamente e de se desinvestir rapidamente". Sua vida líquida "é uma sucessão de reinícios", em que as falhas devem sempre ser escondidas e o sucesso exaltado em constante estratégia existencial consumista (Bauman, 2009, p. 8). Uma vida de consumo traduz também o jogo da autoafirmação, que destrona a duração, promove a transitoriedade e coloca o valor da novidade acima do valor da permanência (Bauman, 2009, 2011). Nesse sentido, o tempo da vida se reduz inteiramente sobre a influência do cálculo econômico e das cifras, apagando as fronteiras sobre o que se se passa dentro e fora da esfera do trabalho (Gorz, 2005). Encontramo-nos em tempo de vida global, na qual é quase impossível manter-se fora do alcance do tempo produtivo (Lazzarato \& Negri, 2001). 


\section{A Experiência: o Desafio de Fotografar}

O relato ilustra a vivência de duas doutorandas e sua professora em disciplina de um Programa de Pós-Graduação em Administração ao longo do segundo semestre de 2016. A disciplina proporcionou a experiência composta de um workshop sobre fotografia, uma visita a uma exposição fotográfica, atividades em sala de aula, o ato de fotografar e de expor as imagens fotografadas em museu da Universidade.

São discutidas as atividades fotográficas realizadas a partir de questões que dizem da relação trabalho, gestão e subjetividade, a fim de refletir sobre o uso da fotografia como potencializador da compreensão teórica na área de conhecimento. Assim, ao apresentarmos uma reflexão de quem sofreu a experiência, no sentido de ressaltar suas próprias atitudes e observações em campo, o presente relato condiz com as observações de Flick (2009).

Enquanto método, aproximamo-nos da autoetnografia (Jones, 2005) que permite ao relato falar por si mesmo; conectar as próprias experiências ao cultural e social; escrever o mundo em estado de fluxo, em movimento entre a história e o contexto. Nas palavras de Jones (2005, p. 765, tradução livre), a autoetnografia consiste em "escolher a cena, contar uma história, tecendo intrigantes conexões entre vida e arte, experiência e teoria, evocação e explanação".

Já no primeiro dia de aula, a turma composta por doze alunos foi instigada a trabalhar a sensibilidade do olhar ao visitar a exposição fotográfica "Trabalho e Subjetividade" integrante de uma atividade de extensão coordenada pela professora e localizada no hall da Escola de Administração da universidade. Ao anotarmos nossas primeiras impressões no caderno de visitas da exposição, pudemos refletir a respeito das peculiaridades do exercício do olhar e da escrita. No segundo encontro da disciplina, juntamente com uma turma de graduação, participamos de um workshop também relativo à atividade de extensão, em que estavam presentes os fotógrafos daquela exposição. Foi um momento de ouvir diferentes vozes e percepções sobre o mundo do trabalho fotografado e reflexões sobre o uso da fotografia na Administração. No decorrer da disciplina, as leituras individuais, os seminários preparados e apresentados pelos alunos em conjunto com a professora, as discussões teóricas nas aulas dialogadas e a elaboração de ensaios teóricos deram embasamento para a atividade proposta que se tornou o foco do presente relato de experiência: o desafio de fotografar!

A atividade consistiu em que cada aluno fizesse fotografias e/ou escolhesse, dentre àquelas de sua autoria e arquivo pessoal, duas que falassem sobre as discussões teóricas realizadas em sala de aula. Como critério, buscou-se capturar aspectos ou indícios da vida social relativa aos modos de trabalhar, tornando-a "mais explícita e completa por meio da imagem", indo ao encontro do que defende Guran (2014, p. 558). Utilizamos, então, a ideia de "fotografia eficiente" (Guran, 2014, p. 560), como sendo "aquela que não é boa, nem espetacular, nem parece uma pintura, mas que é eficiente na sua função de transmitir uma informação para uma determinada finalidade". Ou seja, nossa preocupação estava mais centrada no conteúdo que a imagem poderia transmitir, dentro dos propósitos da disciplina, do que na qualidade técnica ou estética da imagem em si. Cabe citar que quase 
a totalidade das fotografias foi produzida para a atividade e a escolha de apenas duas delas não se mostrou tarefa fácil.

Próximo ao encerramento do semestre, uma sessão específica em sala de aula propiciou que as fotografias fossem apresentadas e intituladas coletivamente. Em prosseguimento, cada aluno deveria montar uma apresentação relacionando as imagens capturadas às teorias estudadas e às sensações e percepções individuais, a fim de que fosse exibida para a turma no último dia de aula. As apresentações revelaram a criatividade e a sensibilidade dos alunos, que conectaram as fotografias, inclusive, a outras formas de expressão, como a literatura e a poesia.

O projeto de extensão coordenado pela professora ganhou repercussão, sendo que somente o caderno da exposição fotográfica "Trabalho e Subjetividade" contou com mais de cem apreciações pessoais voluntárias. Além disso, a exposição foi convidada para tomar espaço no museu da universidade. A professora compartilhou com a diretora do museu a atividade fotográfica desenvolvida na disciplina da pós-graduação e, por considerá-la relevante, os alunos foram convidados a comporem a referida exposição com suas fotografias. Era a nossa vez de participar e alcançar outros públicos.

Ao vivenciar estas atividades tão peculiares e distintas na Pós-Graduação em Administração, surgiu o desejo de compartilhar os saberes vivenciados pelas doutorandas, com o apoio da professora. Assim, para relatar nossa experiência, além da memória das discussões e insights entre as alunas e a professora que serviram de base para escrever o relato do presente artigo, nos valemos do plano de ensino da disciplina, de fotografias produzidas e de ensaios teóricos elaborados ao longo do semestre.

Para a discussão, apresentamos a história por trás das fotografias ao narrarmos brevemente como se deu o desafio de fotografar realidades capazes de estimular a reflexão relativa à relação trabalho, gestão e subjetividade. Desenvolvemos algumas reflexões, através de uma construção textual-imagética que integra as leituras e discussões sobre a base teórica, as idas a campo e a nossa percepção sobre o que dizem as imagens.

\section{Primeira Narrativa: "Tecendo tapetes e coexistências"}

A partir do desafio de fotografar algo que retratasse as discussões teóricas tecidas na disciplina, um dos primeiros questionamentos sobre a atividade em conversa com os colegas depois da aula foi: "como, em uma turma de Pós-Graduação em Administração, uma das atividades da disciplina se relacionaria a tirar fotos?" Ninguém ali era fotógrafo profissional e eu nunca nem tive câmera profissional, o que gerou ansiedade pelo desejo de tirar fotografia que convergisse em significações e que também tivesse estética fotográfica. Mas é claro, todo mundo tira fotos! Eu mesma registrei muitos momentos com a máquina fotográfica analógica dos meus pais, vi a transição para a câmera digital e hoje faço isso simplesmente com o celular, o que aparentemente me possibilitava cumprir a tarefa solicitada.

Durante minha vivência acadêmica era a primeira vez que me deparava com uma atividade como esta, inovadora e inquietante. A inquietação maior era sobre qual conteúdo, como e onde fazer as fotografias. A teoria sobre trabalho, gestão e subjetividade discutida em sala de aula abria um 
espectro enorme de possibilidades, mas para encontrar o melhor registro era necessário mergulhar naquela literatura, para despertar a sensibilidade de enxergar na realidade do cotidiano a subjetividade (Maurente \& Tittoni, 2007; Grisci, 2011) e os não-ditos organizacionais (Cavedon, 2005) que o mundo do trabalho apresenta.

Tendo esta visão como norte, saí para os parques, as ruas, os shoppings, o mercado público, com o celular a postos para muitos cliques. É impressionante como é possível perceber novidades nos mesmos lugares que se costuma passar, quando temos o propósito de descortinar formas de existência em nossa volta e o embasamento necessário para compreendê-las. Na correria do cotidiano costumamos apenas nos cuidar no trânsito, cuidar da nossa segurança, mas a verdade é que há muito a observar sobre trabalhadores e trabalho na vida real. Com estas saídas, eu já tinha muitas fotografias para levar para a aula; o difícil passou a ser escolher apenas duas delas para apresentar. Nesse meio tempo, olhá-las abriu um espaço para outras reflexões.

Flagrei-me pensando sobre o quanto as fotografias são importantes na construção da identidade de uma pessoa, pois nos ajudam a guardar na memória momentos significativos que vivemos. Maurente e Tittoni (2007) comentam sobre estudos em que a fotografia dá suporte ao sujeito para descrever sua visão sobre ele mesmo ou de um ambiente particular. Assim, pensei nas fotografias que eu tinha em casa que contavam minha história de vida. Resgatei em pensamento as organizações em que eu já havia trabalhado e as fotografias que guardo desses locais. Imediatamente lembrei-me da experiência que tive, há sete anos, de trabalhar em outro país e o quanto, na época, eu desejava contar para as pessoas que permaneciam no Brasil, como era surreal trabalhar em uma empresa com uma cultura organizacional e nacional tão distinta da minha. Contudo, parecia que as palavras não bastavam para explicar tantos detalhes, foi então que eu fotografei para ilustrar aquilo que a verbalização não dava conta.

Ao lembrar-me desse fato, surgiu a vontade de rever estas fotografias e, para minha própria surpresa, assim como ressaltam Maurente e Tittoni (2007), eu percebi alguns detalhes nos modos de trabalhar e existência que àquela época eu não dispunha de lentes para conhecê-los. Era esta história que eu queria contar, revisitá-la com outro olhar mais maduro e, dessa vez, acadêmico. Dessa forma, estava decidida qual seria uma das fotografias que levaria para a aula, aquela que foi intitulada "tapete mágico", sobre a qual explano a seguir.

O ano era 2009. Eu, recém-graduada em Administração, fui fazer um intercâmbio para ser trainee em uma fábrica de tapetes e de joias em Jaipur, na Índia. O website da empresa era lindo, o que me provocou a expectativa de trabalhar em uma empresa fabricante e exportadora de produtos finos, de alto padrão.

Ao chegar à Índia, os impactos do choque cultural eram constantes! Calor, poeira, suor, lixo (muito lixo), trânsito caótico, muitas pessoas literalmente empoleiradas no mesmo veículo (motocicleta, ônibus, rikcha), nas ruas homens e mulheres urinando em qualquer canto, homens tomando banho de cócoras (enrolados em uma toalhinha) em torneiras a céu aberto, vacas, elefantes, camelos circulando ao redor. 
Ao chegar na empresa as impressões não foram muito distintas. No meu primeiro dia de trabalho, tive que conferir o endereço e me certificar que era o local certo. Sim, era naquele prédio de quatro andares, cuja entrada dava-se por uma garagem com portão enferrujado e logo na porta havia um homem acocorado sobre um tapete. Era o cara do RH! Apresentei-me e ele foi chamar o dono da empresa para me mostrar a fábrica e conversar sobre o meu trabalho. O empresário queria fazer negócios com o Brasil e eu seria a intermediadora.

Visualmente a empresa não era nem um pouco parecida com o que mostrava o website, tampouco com minhas expectativas. Mas eu estava lá fascinada com a ideia de conhecer uma nova cultura e, ao mesmo tempo, com medo de estar vivenciando aquela experiência em um lugar tão diferente do meu habitual. Afinal, ter uma experiência no exterior seria muito bom para minha carreira, que estava começando, pensava eu, imbuída de uma lógica que agora associo à modernidade-líquida (Bauman, 2009).

Dali em diante, meu dia a dia na empresa durante quase três meses foi conhecer a produção. Foi quando, em um primeiro olhar, me deparei com a realidade de uma fábrica com características tais quais são descritas por Deleuze (1992), Gaulejac (2007), Mansano (2009) nas sociedades disciplinares, e por Bauman (2009) na modernidade sólida. Os tapetes eram todos feitos manualmente, apenas com o apoio de algumas ferramentas manuais. Um tapete médio de sala, por exemplo, levava em torno de três meses para ficar pronto. A produção feita à mão agrega valor, o que possibilitava os tapetes serem vendidos para a Itália e os Estados Unidos por milhares de dólares. Já as joias mostradas no website, descobri que não eram fabricadas na empresa, eram "negócio para estrangeiro ver". Na planta da fábrica eram feitas bijuterias de baixíssima qualidade, como brincos e pulseiras, também para exportação. Esse é o sistema de sentido dado pela empresa, um universo gerencialista em que a subjetividade é mobilizada por resultados, por sucesso financeiro, que tende a excluir o que não é rentável (Gaulejac, 2007).

Tive algumas conversas com o dono da empresa, o gerente dos tapetes e o gerente das bijuterias. Conversava com eles em inglês. O proprietário andava muito bem vestido, usava joias como pulseiras, anéis, correntes, tinha um carro de luxo e estava sempre ocupado com dispositivos eletrônicos. Ao jogar seu nome na internet dava para ver que ele era um empresário importante na cidade. Já os gerentes, eram mais simples, mas também bem vestidos, participavam da sociedade e faziam bem o seu papel de supervisionar diariamente seus setores. Realidade caricata da lógica dos managers dominados por seus desejos de onipotência, pois não podem ser tratados como a categoria dos empregados, mas presos à empresa e ofuscados pela ameaça de serem dispensados. Da mesma forma, a lógica dos acionistas interessados na busca das altas taxas de rentabilidade (Gaulejac, 2007).

No entanto, meu dia a dia se passava com os funcionários do chão de fábrica, que trabalhavam literalmente no chão, sentados ou de cócoras. A vestimenta dos homens compunha-se de roupa velha e rasgada, já as mulheres usavam sári simples, mas mais cuidado. Com eles, eu me comunicava por mímica e poucas palavras em inglês, já que na Índia só fala inglês quem vai para a escola. Os funcionários só falavam hindi e tinham um rosto com aparência sofrida, mas apesar disso sorriam sempre nos 
intervalos em que iam tomar tchai. Uma das funcionárias levava a sua bebê para o trabalho e ela ficava em cima de um pano no chão, com as fraldas e roupa umedecidas pela falta de troca. Conheci a casa delas: no caminho parecia que estava em uma das favelas que temos no Brasil, casinhas muito pequenas e mal-acabadas, sem saneamento básico, ratos passavam perto dos nossos pés. A casa era uma peça de aproximadamente $10 \mathrm{~m}^{2}$, em que moravam as duas, mais a mãe e o esposo da funcionária.

Ao conhecer um pouco da realidade das diferentes categorias que trabalhavam naquela fábrica, fica claro o indício da dupla vantagem do patronato em relaçãoàmassa de operários que eram vigiados constantemente, bem como descreve Deleuze (1992) sobre a sociedade disciplinar. Isto se vê claramente na questão dos salários e poder aquisitivo das categorias: "a fábrica era um corpo que levava suas forças internas a um ponto de equilíbrio, o mais alto possível para a produção, o mais baixo possível para os salários" (Deleuze, 1992, p.2). O pagamento dos empregados não era proporcional à produtividade real e aos preços dos produtos, tal como aponta Gaulejac (2007) sobre a remuneração que não está relacionada à qualidade ou à quantidade de trabalho fornecido. Nem interessa o desempenho coletivo, já que a remuneração é individualizada. Assim ocorre com o valor do trabalho, que não está ligado à qualidade da atividade concreta, pois os discursos já são interiorizados em cada papel exercido na organização.

Dentre os funcionários, o que mais me chamou a atenção foi o indiano no tear, ilustrado na fotografia 1. Parecia uma típica cena de uma fábrica da sociedade disciplinar. Um meio de confinamento de operários condenados à concentração total naquele tempo e espaço. Ou, como denomina Bauman (2009), essa foto faz parecer que estamos de volta à modernidade sólida, em que se configurava o trabalho racional, uniforme, disciplinado, em que as mãos eram treinadas e vigiadas de forma direta pela empresa.

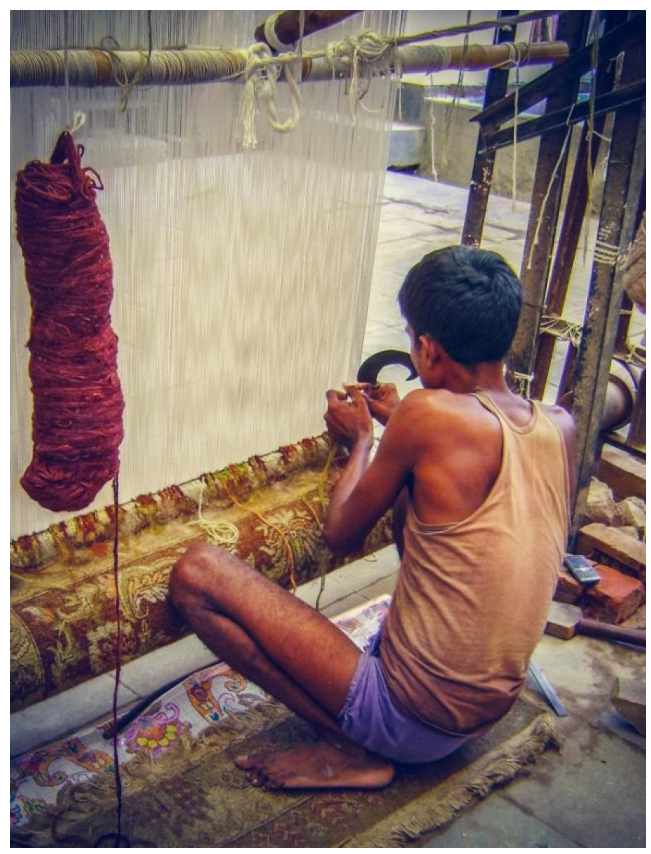

Fotografia 1: "Tapete Mágico"

Fonte: fotografia de uma das autoras (2009). 
Não sei o seu nome! Na época eu até sabia o nome de alguns funcionários com quem eu tentava dialogar mais, mas o dele não. Ele era quieto, sério e passava o dia inteiro acocorado, concentrado no seu tapete. Seu trabalho era ler o quadriculado do desenho, seu tamanho e cor, pegar a lã para transpassar no tear. Mais uma característica da sociedade disciplinar em pleno século XXI, usar máquinas simples (Deleuze, 1992), como a foice que aparece na fotografia que servia para arrematar os fios, algo que ilustra a coexistência no mundo do trabalho (Deleuze \& Guattari, 2011).

O trabalho desse indiano, em um primeiro olhar, parece material: produzir tapetes manualmente. Uma atividade repetitiva e fisicamente desgastante. Contudo, muita coisa acontece entre a mente e a mão! Há ali um trabalho imaterial incorporado (Gorz, 2005). Há uma complexidade relativa à leitura dos desenhos: quanto maior a quantidade de pontos, menores eles são e maior é a sua nitidez; o suave dégradé das cores, a perfeição no alinhavar que só pode ser feito pelas mãos habilidosas de quem sabe o que faz. $O$ ato deste trabalho, que se ilustra na exata posição do corpo para determinar o ritmo, a pressão da mão em relação aos nós, a acuidade para o discernimento dos fios emaranhados em diversas cores, a dimensão espacial vislumbrada na transposição do desenho aos fios, "se perde em um sistema complexo, abstrato, desterritorializado, que não permite ao agente circunscrever concretamente os frutos de sua atividade" (Gaulejac, 2007, p. 151).

Eu sentia dores nas minhas pernas só de observar que ele ficava naquela posição por toda uma manhã e tarde. Nem das conversas que às vezes surgiam entre os outros funcionários ele participava, se mantinha concentrado. As paradas eram para ir almoçar e para os intervalos de tomar tchai. Em um desses intervalos, vi esse homem levantar pela primeira vez e me pareceu que suas pernas estavam atrofiadas.

Sua produção era lenta, porém constante e fiscalizada pelo gerente. Presenciei algumas vezes cenas em que os funcionários estavam "morcegando" (embromando no trabalho), às vezes até "pescando" (quase dormindo) em cima de suas atividades, e chegou o gerente. Era uma cena de susto e todos voltavam rapidamente aos seus afazeres. Bem como se descreve a sociedade disciplinar, em que o homem é vigiado diretamente por outros que detém o poder, representantes da organização. É a mão de obra disciplinada no modo organizativo do processo de trabalho e de produção. "O indivíduo foi amplamente investigado e submetido a um sistema de vigilância especializado, que se ocupava em fazer respeitar todo um conjunto de referências às leis e normas. Assim a disciplina foi aos poucos internalizada nas massas no capitalismo vigente" (Mansano, 2009, p. 31).

Percebo, portanto, como a mundialização induziu à desterritorialização do poder econômico, conforme discorrem Gaulejac (2007) e Deleuze e Guattari (2012). O lugar da atividade concreta está desligado dos lugares de tomada de decisão. Mesmo assim, os trabalhadores ainda são considerados submissos às exigências de quem tem o poder decisório. Essas empresas vendem seus produtos ou matéria-prima para multinacionais que controlam direta ou indiretamente mais da metade da produção econômica mundial. Nesse sentido, ocorre uma transformação nas relações entre o capital e o trabalho. "A desterritorialização do capital corresponde a reterritorialização do trabalho" (Gaulejac, 2007, p. 57), tendo em vista a exploração da mão de obra em países asiáticos como a Índia. 


\section{Segunda Narrativa: "Subjetividade (Re)velada"}

Como fotógrafa amadora no meu tempo livre, já se apresentava uma relação de proximidade estabelecida entre mim e a fotografia. Desde que comecei a me aventurar pelo mundo dos registros fotográficos, sempre me senti desafiada a treinar o olhar para captar, através da câmera, o que a velocidade de um acontecimento não nos permite congelar na mente e, às vezes, sequer perceber. Ao receber da professora o desafio de trabalhar com fotografia como uma atividade da disciplina, fiquei ao mesmo tempo feliz - poderia sair a fotografar com o propósito de estudar - mas também apreensiva - como registrar em imagens conceitos de densidade teórica tão profunda como os que estavam sendo trabalhados?

Foram diversas ideias elucubradas até que optei por retratar as atividades desenvolvidas em um estúdio de tatuagem, por entender que a relação ali existente entre labor e arte estava muito próxima do conceito de trabalho imaterial explorado por Grisci (2011). As capacidades intelectuais e criativas do tatuador, desenhadas na pele de seus clientes, remontam também às suas competências comportamentais - produtos intangíveis do seu trabalho - capazes de suscitar nos clientes "sentimentos de confiança, segurança e conforto" (Grisci, 2011, p. 456).

Estabeleci o primeiro contato com o estúdio, expliquei o projeto e, sendo prontamente acolhida, estava convencida de estar no caminho certo. Lá chegando, no dia e hora marcados, fui informada de que o cliente havia desmarcado e, portanto, nada haveria para registrar. Assim, visivelmente decepcionada, foi de forma muito gentil que recebi de Danilo², o bodypiercer que trabalha no mesmo estúdio, a sugestão de retratar o seu trabalho.

As fotografias apresentadas nesta narrativa surgiram desta pequena história. Tal como nos expõe Samain (2012, p. 160), elas são "confidências, memórias, arquivos" de um breve momento de busca de conhecimento. Uma modesta e singular tentativa de oposição à "banalização, desses dilúvios de imagens que conhecemos, excessos que nos cegam" (Samain, 2012, p. 162), de um tempo pós-moderno, tecnológico, em que deixamos de fotografar o mais importante para fotografarmos absolutamente tudo.

Mansano (2009) atenta para o fato de que, nessa nova fase, o que vale já não é o produto em si, mas sim a exploração das novas "formas de vida" a que estes produtos estão atrelados. O trabalhador do imaterial, agora imerso em um novo contexto de produção e consumo, já não pode mais fixar-se no produto físico de seu trabalho: envolve-se com ele desde o processo de concepção e construção desses novos modos de viver, do qual é produtor e consumidor ao mesmo tempo. As transformações a que este trabalhador foi exposto não se restringiram, portanto, a aprender a lidar com a redução dos postos formais de trabalho ou com a precarização das vagas remanescentes. Ele próprio precisou transformar-se para manter-se ativo e produtivo e assim garantir sua subsistência. Adaptou-se. Entrou no jogo. Ainda que, para Bauman (2009), participar desse jogo não seja exatamente uma escolha, já que inexiste a opção de ficar fora dele. Na mesma linha, Gorz (2005, p. 20) afirma que o sujeito não pode ser obrigado nem dispensado da tarefa "de se fazer, ele mesmo, o que ele é".

2 Nome fictício 
Danilo, enquanto fazia o seu trabalho, relata toda a preocupação com a assepsia, um cuidado cirúrgico no modo como conduz a sua atividade. Orgulhoso da sua atividade, afirma que este conhecimento, adquirido ao longo da sua vida laboral em muitos cursos, palestras e congressos nacionais e internacionais dos quais é participante assíduo, é o que o diferencia dos demais colegas de profissão. A fotografia 2 busca mostrar o conhecimento e o envolvimento de Danilo com o seu trabalho. Enquanto manuseava o material, ainda nos preparativos para a aplicação da joia, explicava em minúcias a utilidade de cada objeto: pinças, agulhas, toucas, cotonetes, líquidos esterificadores (os quais não ouso tentar repetir os nomes!), reforçando a importância da sua utilização adequada, uma vez que o desconhecimento ou mal-uso poderia decorrer infecções nos clientes. A preocupação com a estética, diz ele, não pode sobrepujar a preocupação com a saúde. Dedos ágeis envoltos por luvas - mas não quaisquer luvas: essas são esterilizadas, não as comuns que se compra por aí! - juntam-se à serenidade da voz e conduzem com delicadeza a tensa cliente que espera pelo momento em que, da dor, irá surgir a beleza do enfeite. Sozinho no estúdio, ao soar da campainha, Danilo para o que está fazendo, ausentando-se da sala para atender ao chamado. Ao retornar, o descarte do material contaminado pela evasão do ambiente estéril marca o reinício do processo.

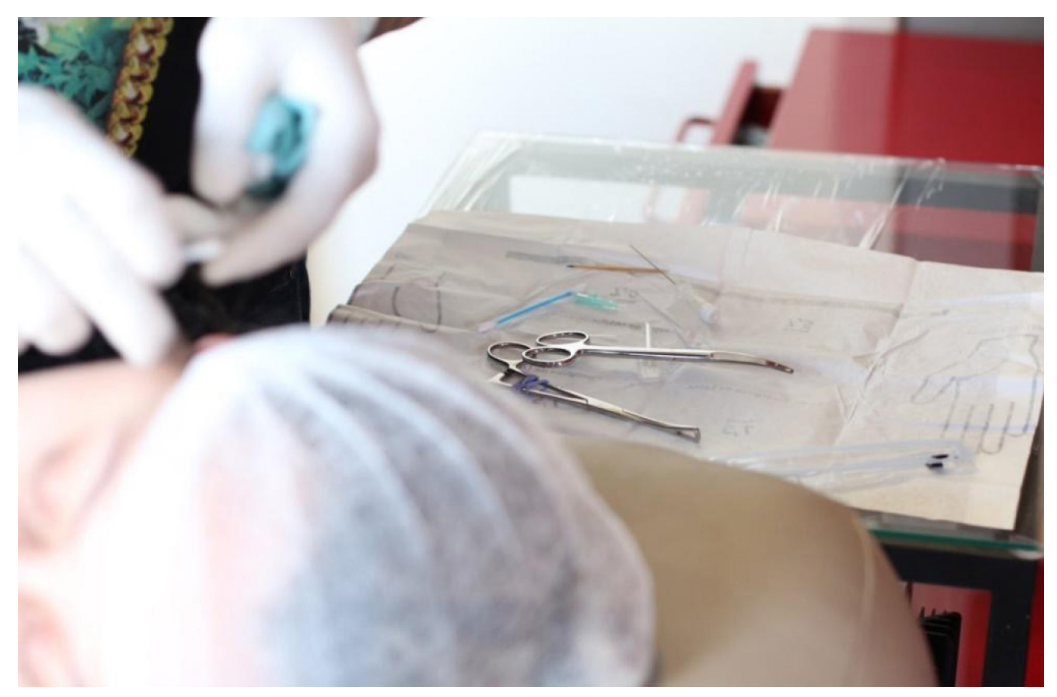

Fotografia 2: "Estética"

Fonte: fotografia de uma das autoras (2016).

Para Gorz (2005, p. 20), o sujeito produz-se "a si mesmo" e o fruto do seu trabalho, ao não produzir somente o palpável, é traduzido por um "saber vivo" que se tornou "a fonte mais importante da criação de valor". É o jeito de ser que se torna produtivo e é exatamente a atividade dessa produção de si mesmo a base do trabalho imaterial. Para Mansano (2009), o que conta são os saberes da experiência, do discernimento, da capacidade de coordenação, de auto-organização e de comunicação adquiridos cotidianamente e não apenas através de qualificação técnica, formal. Danilo expõe na parede de seu estúdio os diversos prêmios que já recebeu e os certificados dos congressos que participou, como ouvinte ou como avaliador convidado. 
Para Lazzarato e Negri (2001), o trabalho imaterial está no centro da relação produção-consumo, ativando-a e organizando-a. Por isso, as capacidades afetivas, comunicativas e interativas dos trabalhadores são fundamentais para retroalimentar o sistema: a produção de novos estilos de vida, que demandam novas formas de trabalhar, que sustentam novos estilos de vida, aproximando produtores e consumidores. Assim:

A particularidade do trabalho imaterial é que seu produto, ao ser consumido, não mais permanece com o consumidor como permaneceria o produto do trabalho material - mas ele é produtivo porque transforma o consumidor naquilo que diz respeito ao seu modo de pensar e agir, a seu estilo de vida (Grisci, 2011, p. 457).

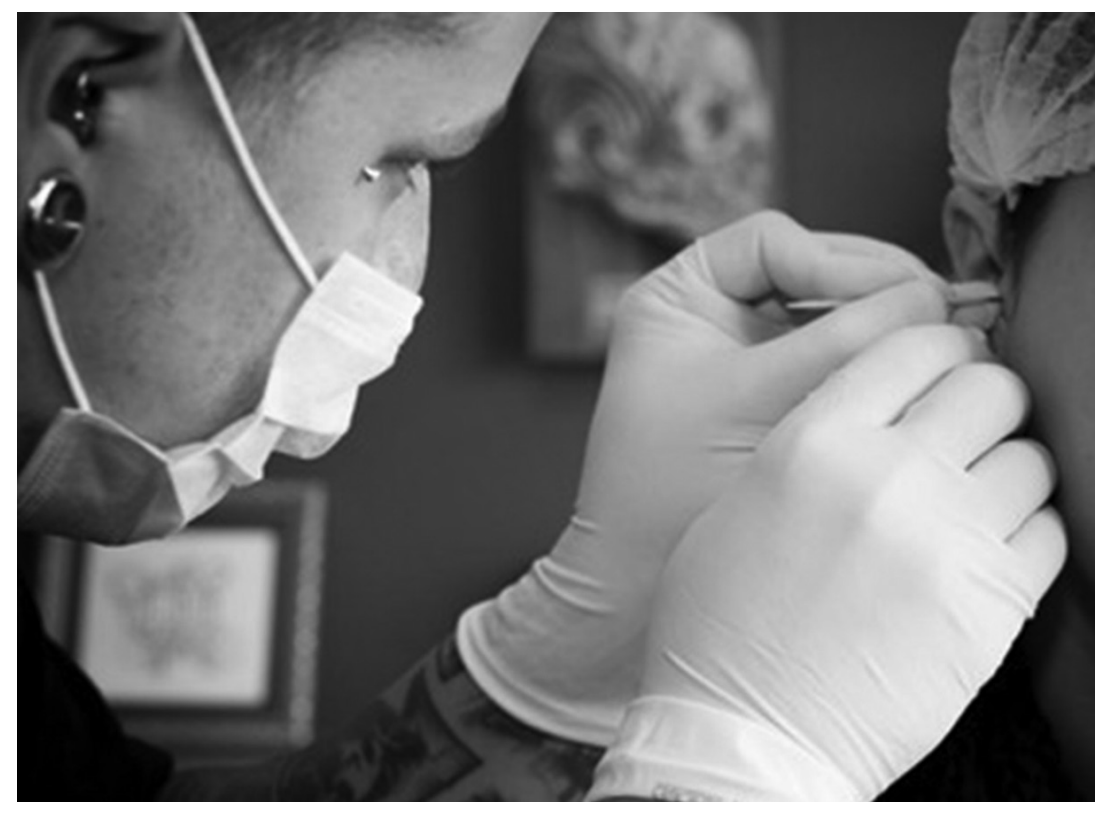

Fotografia 3: "Transformações"

Fonte: fotografia de uma das autoras (2016).

Trata-se, para Gorz (2005), de uma mobilização completa e voluntária do sujeito, que já não é capaz de distinguir o tempo de trabalho do tempo de não-trabalho. Danilo é, ele mesmo, o trabalho que realiza. A mobilização de um trabalhador que busca sua autorrealização e que cede ao trabalho o "seu corpo, seu psiquismo, sua linguagem, sua comunicação (...), sua vida inventiva" é fomentada por uma relação de consumo baseada na "substituição constante de mercadorias" que vê na subjetividade uma "fonte de produção de riqueza" (Mansano, 2009, p. 519).

Danilo, retratado em ação na fotografia 3, cristaliza no corpo de outrem o resultado de seu trabalho. O olhar sagaz contracena com o próprio corpo transformado em vitrine. A delicadeza e a precisão do toque são demonstradas na serenidade do olhar da cliente que busca incorporar a arte que embeleza. Toda a cena, recortada aqui pelas fotografias expostas, em nada lembra o estereótipo, ainda vigente, que enxerga tatuadores e bodypiercers como "desviantes, marginais, criminosos, rebeldes" (DeLuca \& Rocha-de-Oliveira, 2015). Ao contrário, o modo tranquilo de Danilo trabalhar aproxima sua atividade da arte, e as demonstrações de domínio da técnica corroboram com os certificados pendurados na parede. 
Com o amainar das fronteiras entre trabalho e não-trabalho, "no limite, não é mais o sujeito que adere ao trabalho; mais que isso, é o trabalho que adere ao sujeito" (Gorz, 2005, p. 22). Na própria vida que é transformada em business, o sujeito "auto empreendedor" se autoexamina, se autocritica e se autocensura, "obrigando-se a impor a si (...) constrangimentos necessários para assegurar a viabilidade e a competitividade da empresa que ela é" (Gorz, 2005, p. 22). A "venda do si", diz o autor, afeta todas as instâncias da vida, e nem mesmo o "desenvolvimento pessoal mais íntimo" escapa da esfera econômica, uma vez que conduz a "uma melhor estabilidade emocional, a uma abertura relacional mais natural, a uma acuidade intelectual melhor dirigida, e, assim, a um melhor desempenho econômico" (Gorz, 2005, p. 25).

No estúdio de Danilo, uma pequena estante exibe livros de renomados artistas: Joan Miró, Sebastião Salgado, Wojtek Siudmak, Gil Elvgren, Mirella Ferrera. A inspiração dos tatuadores e bodypiercers que ali trabalham vem da arte! Tocou-me perceber que, em um mundo onde o pensamento econômico é preponderante, a sensibilidade da arte ainda tem espaço para inspirar, tocar, seduzir, alterar. Os corpos transformados pelo trabalho de Danilo e seus colegas exibem coexistências: o belo e o econômico, a fonte de inspiração e a fonte de renda, a arte e o business.

\section{Modos de Estudar e a Arte Fotográfica: reflexões}

A arte transforma. A arte fotográfica, utilizada no contexto da disciplina cursada, tomada no presente relato como provocadora do pensar e como catalisadora de uma melhor apreensão teórica, foi ao encontro do exposto por Davel, Vergara e Ghadiri (2007): foi fonte de inspiração, de conhecimento, de interpretação, de expressão, de comunicação.

Enquanto estudantes de pós-graduação, havemos de considerar os múltiplos papéis que somos desafiados a interpretar nos contextos de ensino-aprendizagem, pesquisa e extensão. Como estudantes, docentes e pesquisadores da área de Administração, o desenvolvimento de novos modos de estudar vêm ao encontro do favorecimento de uma apreciação mais crítica e reflexiva das realidades organizacionais, em especial das formas como se apresentam as práticas de trabalho e de gestão no cotidiano.

É preciso manter, enquanto estudantes, um constante exercício de reaprender a aprender, como nos apontam Pecharromán e Pozo (2006, p. 179), em um esforço de reinterpretação de uma "epistemologia intuitiva", muitas vezes soterrada pelo objetivismo epistemológico a que somos conduzidos a utilizar quando se trata de ciência. Assim, como estudantes, a atividade fotográfica desenvolvida e explicitada neste relato, de experimentar a arte em conexão com a teoria, nos forçou a sair da zona de conforto, nos perturbou, possibilitou valer-nos de outros sentidos que não aqueles normalmente utilizados em Administração. Permitiu-nos fugir da lógica do resultado, do pragmatismo e da objetividade.

Além de nós, as autoras deste relato, outros alunos da disciplina compartilharam da inusitada sensação de que, mesmo sem portar uma câmera, os nossos olhos não mais paravam de fotografar as cenas laborais 
cotidianas até então invisíveis para nós. No restaurante, no parque, no supermercado, na agência bancária - o mundo do trabalho e os sujeitos que o transformam e por ele são transformados visibilizavam-se nas cenas corriqueiras como que para nos mostrar que a teoria esteve sempre ali, o tempo todo.

Nós, o conjunto de alunos da disciplina em questão de um curso de pós-graduação, encerramos o semestre transformados pela experiência vivida. Os reflexos positivos se estendem para o exercício do compartilhamento de conhecimento que nos propomos a adotar, enquanto docentes, e para o desenvolvimento da ciência que nos propomos a fazer, enquanto pesquisadores.

Como docentes, cientes da relevância social do processo de ensino-aprendizagem e conectados ao contexto em que estamos inseridos, é fundamental considerar que a demanda constante por novos saberes, conhecimentos e habilidades é característica do período em que vivemos. Assim, em conjunto com o que nos aponta Pozo (2002), afirmamos que se faz necessário o surgimento de uma relação professor-aluno que vá além da mera reprodução de conhecimentos, mas que esteja embasada na aceitação da existência de múltiplos saberes. Como docentes, precisamos contribuir para a criação de uma "nova cultura de aprendizagem" não apenas como resposta às exigências de uma sociedade cada vez mais acelerada, mas principalmente como forma de compreendê-la e de nos situarmos criticamente em relação a ela (Pozo, 2002, p. 26).

A utilização da arte como recurso pedagógico no processo de ensino-aprendizagem, relatada no presente artigo através da atividade fotográfica, possibilita concomitantemente concentrar e ampliar as experiências vividas. Estas experiências, quando vinculadas às emoções dos sujeitos, ajudam no desenvolvimento cognitivo dos alunos e são fundamentais para o aprendizado (Davel, Vergara \& Ghadiri, 2007). A adoção de uma postura favorável à observação, à criatividade e à inovação, porém, requer dos professores a coragem de ir ao encontro do imprevisto e do inesperado, uma vez que coloca o aluno no centro do processo.

Assim, no papel de docente em outra instituição de ensino, uma das alunas deste relato viu-se encorajada pela experiência vivenciada a utilizar a fotografia em duas turmas de Graduação em Administração, solicitando aos seus alunos que também fossem a campo e registrassem em imagens suas impressões sobre os temas estudados na disciplina que cursavam. $O$ resultado, além dos debates realizados em sala de aula, foi uma exposição de cordel no saguão da universidade em que atua como docente, com retornos positivos dos alunos e da comunidade acadêmica que presenciou a exposição. A utilização da fotografia como atividade de extensão, ao permitir a interação entre a universidade e a comunidade colaborou para aproximar teoria e prática e para dar visibilidade ao trabalho acadêmico.

No campo da Administração, ao aceitar a vida organizacional como um fenômeno complexo, ambíguo e paradoxal, tal como defende Morgan (1996), compreendemos que a leitura objetiva de uma determinada realidade pode não abarcar todo o emaranhado de possibilidades que se apresentam. É do encontro do "pensamento disciplinado" com a "capacidade criativa" que 
podem surgir novas formar de enxergar, compreender e solucionar questões organizacionais (Morgan, 1996, p. 20). Defendemos, como pesquisadoras em Administração e por meio da experiência vivenciada e relatada, que o uso da arte possibilita outras formas de conexão entre teoria e prática e outras formas de diálogo. Entendemos que, assim, viabiliza-se o surgimento de outras possibilidades de exploração e entendimento das intrincadas e multifacetadas relações acerca dos processos organizacionais, em especial do mundo do trabalho e suas consequências para os modos de viver.

A utilização de recursos imagéticos no desenvolvimento de pesquisas em Administração trouxe significativas contribuições para o campo ${ }^{3}$, ainda que, na visão de Ipiranga (2016), sejam poucos os estudos que se utilizam de métodos visuais na investigação científica. O desafio epistemológico de vencer a barreira do conservadorismo requer pesquisadores que, ao verem as potencialidades da fotografia, se aventurem a utilizá-la.

Ao defendermos a interação da arte, em especial da fotografia, com a exploração de novos modos de estudar no contexto do ensino-aprendizagem, da pesquisa e da extensão em Administração, é necessário esclarecermos que reconhecemos a importância do rigor metodológico exigido pela ciência. Em concordância com Demo (2000), reforçamos a necessidade de se observar os critérios de coerência, de sistematicidade, de consistência, de originalidade, de objetivação e de discutibilidade - características fundamentais do que é científico. Apelamos, porém, para uma maior valorização da experiência subjetiva. Afinal, "o conhecimento científico não produz apenas certezas, mas fragilidades mais controladas" (Demo, 2000, p. 26).

\section{Considerações Finais}

O presente artigo, através da apresentação das narrativas e reflexões das vivências de uma experiência em sala de aula, permitiu evidenciar que o uso da fotografia se mostrou como elemento potencializador da compreensão teórica em Administração. As fotografias apresentadas, juntamente às experiências relatadas, possibilitaram refletir, para além dos trabalhos de um operário em uma fábrica de tapetes e de um bodypiercer, a subjetividade em diferentes contextos temporais, culturais, econômicos e sociais, trazendo luz a situações de trabalho e gestão que outrora os olhos não seriam capazes de olhar.

Argumentamos, desse modo, em favor da interação da arte com os processos de ensino-aprendizagem e de produção científica, por compreender que a experiência relatada levou os integrantes de uma disciplina de um curso de pós-graduação a uma qualificação do olhar e, por consequência, possibilitou novas formas de apreensão da teoria em campo. Tal como exposto por Morgan (1996, p. 388), "a realidade é, ao mesmo tempo, subjetiva e objetiva". Ao considerarmos isso, podemos contribuir

3 Ipiranga (2016) constrói um panorama e analisa as diversas publicações que utilizaram recursos imagéticos em pesquisa no Brasil, ao longo dos últimos anos. Para mais informações, sugerimos consultar o texto original. Aos trabalhos citados pela autora, incluímos ainda o trabalho de Prestes e Grisci (2016). 
para descortinar alguns aspectos da realidade organizacional e do mundo do trabalho. Assim, pensamos ter nos aproximado do argumento de Mansano (2009, p. 522): "uma análise que envolva a mera oposição entre indivíduo e capital já não dá mais conta de lidar com a complexidade que ora vivemos nesta esfera da existência".

No presente artigo, buscamos compartilhar a transformação por nós vivenciada como resultado da união entre arte e produção científica. Nós, o conjunto de alunos da disciplina, nos vimos sensibilizados a abdicar, ainda que temporariamente, de uma objetividade que há muito nos acompanha. Como docentes, cientes da nossa responsabilidade social na construção de um mundo melhor para as gerações futuras, nos descobrimos provocados a instigar, em nossos próprios alunos, as mesmas inquietações que vivenciamos, de modo a contribuir para a formação de sujeitos críticos e reflexivos. Como pesquisadores, nos abrimos a novas possibilidades na tentativa de melhor compreender as realidades sociais que nos cercam.

Reforçamos, utilizando-nos de determinadas lentes teóricas sobre o mundo do trabalho contemporâneo, que a fotografia ajudou a fazer surgir outras possibilidades de reflexão sobre a complexidade do tema. Assim, confiamos que a exploração dessa problemática, em conjunto com a fotografia, poderia ser trabalhada a partir de diversos enfoques, superando, de acordo com o argumento de Prestes e Grisci (2016), a utilização da arte fotográfica apenas como recurso relativo à coleta de dados. Cremos que a fotografia pode servir de elemento capaz de oportunizar novas conexões entre teoria, campo e novos meios de interpretação das realidades organizacionais. Desta forma, como sugestões de pesquisas futuras, e dentre os vários caminhos que se apresentam nos estudos sobre os modos de trabalhar e viver, propomos: a utilização da fotografia à compreensão de não-ditos organizacionais; estudos longitudinais construídos por meio da interpretação dos registros fotográficos em diferentes momentos históricos; análise da perspectiva do olhar de diferentes profissionais a respeito de suas realidades cotidianas, utilizando-se de imagens pré-definidas ou produzidas pelos próprios atores.

Por fim, ressaltamos que, com este relato, não temos a intenção de esgotar a discussão sobre o uso da fotografia em conjunto com os processos de ensino-aprendizagem, pesquisa e extensão, tampouco elaborar conclusões ou fechamentos definitivos. Acreditamos na arte a favorecer à reflexão de modos de trabalhar e de viver. Entendemos que, para além de um objetivismo científico redutor, por meio da fotografia, alunos, professores e pesquisadores poderão congregar e convergir à compreensão das realidades que nos cercam e que ajudamos, cotidianamente, a construir. 


\section{Referências}

Bauman, Z. (2009). Vida Líquida (2a ed.). Rio de Janeiro: Zahar.

Bauman, Z. (2011). Vida em Fragmentos: sobre a ética pós-moderna. Rio de Janeiro: Zahar.

Cavedon, N. R. (2005). Fotoetnografia: a união da fotografia com a etnografia no descortinamento dos não-ditos organizacionais. Organizações \& Sociedade, 12(35), 13-27.

Davel, E., Vergara, S. C., \& Ghadiri, D. P. (Orgs.). (2007). Administração com Arte: Experiências vividas de ensino-aprendizagem. São Paulo: Atlas.

Deleuze, G. (1992). Conversações. São Paulo: Editora 34.

Deleuze, G., \& Guattari, F. (2011). Mil Platôs: Capitalismo e Esquizofrenia (Vol. 1, $2^{a}$ ed.). São Paulo: Editora 34.

Deleuze, G., \& Guattari, F. (2012). Mil Platôs: Capitalismo e Esquizofrenia (Vol. 5, $2^{\mathrm{a}}$ ed.). São Paulo: Editora 34.

DeLuca, G. \& Rocha-de-Oliveira, S. (2015). Desenhando uma Trajetória Profissional no Campo da Tatuagem. Anais do Encontro da ANPAD, Belo Horizonte, MG, Brasil, XXXIX.

Demo, P. (2000). Metodologia do Conhecimento Científico. São Paulo: Atlas.

Demo, P. (2001). Pesquisa: princípio científico e educativo. São Paulo: Cortez Editora.

Fernandes, M. E. (2011). Imagem e olhar em pesquisa: para além do visível. Revista Hospitalidade, 8(2), 38-51.

Flick, U. (2009). Uma introdução à pesquisa qualitativa ( $3^{a}$ ed.). Porto Alegre: Bookman.

Gaulejac, V. (2007). Gestão como Doença Social: ideologia, poder gerencialistas e fragmentação social. São Paulo: Ideias e Letras.

Godoi, C. K., \& Uchoa, A. G. F. (2016, outubro). Metodologia Qualitativa Discursivo-Imagética: do contexto da produção às possibilidades de recepção da imagem. Anais do Congresso Brasileiro de Estudos Organizacionais, Porto Alegre, RS, Brasil, IV.

Gondim, S. M. G., Feitosa, G. N., \& Chaves, M. (2007). Imagem do Trabalho: um Estudo Qualitativo Usando Fotografia em Grupos Focais. Revista de Administração Contemporânea, 4(11), 153-174.

Gorz, A. (2005). O Imaterial: conhecimento, valor e capital. São Paulo: Annablume.

Grisci, C. L. I. (2011). Trabalho Imaterial. In A. D. Cattani, \& L. Holzmann. Dicionário de Trabalho e Tecnologia. Porto Alegre: Zouk.

Guran, M. (2011). Considerações sobre a constituição e a utilização de um corpus fotográfico na pesquisa antropológica (Relatório final de Pós-Doutorado/ 2004-2005 - Autorizado para publicação em Rio de Janeiro/2011), São Paulo, SP, Programa de Pós-Graduação em Antropologia Social da Faculdade de Filosofia Letras e Ciências Humanas da USP, Universidade de São Paulo.

Guran, M. (2014). Identidade Agudá espelhada no tempo: fotografia como instrumento de pesquisa social - um relato de experiência. Boletim do Museu Paraense Emílio Goeldi Ciências Humanas, 2(9), 557-565. 
Ipiranga, A. S. R. (2016, outubro). A Imagem Fotográfica como uma Questão de Método. Anais do Congresso Brasileiro de Estudos Organizacionais, Porto Alegre, RS, Brasil, IV.

Jones, S. H. (2005). Autoethnography: making the personal political. In N. K. Denzin, \& Y. S. Lincoln. Handbook of Qualitative Research (3rd ed.). Sage Publications: Thousand Oaks, California.

Junquilho, G. S., \& Gonçalves, M. G. D. (2007). Fotografia no ensino e aprendizagem da consultoria. In E. Davel, S. C. Vergara, \& D. P. Ghadiri (Orgs.) Administração com Arte: experiência vividas de ensino-aprendizagem. São Paulo: Atlas.

Lazzarato, M., \& Negri, A. (2001). Trabalho Imaterial: formas de vida e produção de subjetividade. Rio de Janeiro: DP\&A.

Madden, L. T., \& Smith, A. D. (2015). Using photographs to integrate liberal arts learning in Business Education. Journal of Management Education, 1(39), 116-140.

Mansano, S. R. V. (2009). Transformações de subjetividade no exercício do trabalho imaterial. Revista Estudos e Pesquisas em Psicologia, 2(9), 512-524.

Mansano, S. R. V., \& Carvalho, P. R. (2015). Políticas de subjetivação no trabalho: da sociedade disciplinar ao controle. Psicologia em Estudo, 4(20), 651-661.

Maurente, V., \& Tittoni, J. (2007). Imagens como estratégia metodológica em pesquisa: a fotocomposição e outros caminhos possíveis. Revista Psicologia e Sociedade, 3(19), 33-38.

Morgan, G. (1996). Imagens da Organização. São Paulo: Atlas.

Paço-Cunha, E. (2009). Administração com Arte. (Resenhas Bibliográficas). Revista de Administração Contemporânea, 4(13), 700-701.

Pecharromán, I., \& Pozo, J. I. (2006). ¿Cómo sé que es verdad?: epistemologías intuitivas de los estudiantes sobre el conocimiento científico. Investigações em Ensino de Ciências, 2(11), 153-187.

Pozo, J. I. (2002). Aprendizes e Mestres. Porto Alegre: Artmed Editora.

Prestes, V. A., \& Grisci, C. L. I. (2016, julho). Trabalho imaterial de modelo de moda: a fotografia como lugar de memórias e recurso disparador da fala. Anais do Congresso Ibero-Americano em Investigação Qualitativa, Porto, Portugal, 5.

Ray, J. L., \& Smith, A. D. (2012). Using Photographs to Research Organizations: Evidence, Considerations, and Application in a Field Study. Organizational Research Methods, 2(15), 288-315.

Samain, E. (2012). As peles da fotografia: fenômeno, memória/arquivo, desejo. Visualidades, 1(10), 151-164.

Tittoni, J., \& Nardi, H. C. (2011). Subjetividade e Trabalho. In A. D. Cattani, \& L. Holzmann. Dicionário de Trabalho e Tecnologia. Porto Alegre: Zouk.

Uchoa, A. G. F., \& Godoi, C. K. (2016, outubro). Metodologias Qualitativas de Análise de Imagens: origem, historicidade, diferentes abordagens e técnicas. Anais do Congresso Brasileiro de Estudos Organizacionais, Porto Alegre, RS, Brasil, IV. 